\title{
La salud pública en la Argentina en tiempos de coronavirus*
}

\author{
Public health in Argentina in \\ the time of coronavirus
}

\section{Karina Inés Ramacciotti ${ }^{i}$ \\ ' Investigadora y docente, Departamento de Ciencias Sociales/ Universidad Nacional de Quilmes/ Consejo Nacional de Investigaciones Científicas y Tecnicas. \\ Ciudad Autónoma de Buenos Aires - Argentina \\ orcid.org/0000-0002-6724-3926 \\ karinaramacciotti@gmail.com}

Recebido em 15 ago. 2020.

Aprovado em 13 set. 2020.
RAMACCIOTTI, Karina Inés. La salud pública en la Argentina en tiempos de coronavirus. História, Ciências, Saúde - Manguinhos, Rio de Janeiro, v.28, n.1, jan.-mar. 2021, p.301-305.

\section{Resumen}

El surgimiento de los primeros casos de coronavirus en Argentina puso en discusión las características del sistema de salud y sus formas de acceso a los servicios y prestaciones. En esta intervención se revisan los momentos en los cuales se produjeron modificaciones en el proceso de adquisición de los derechos sanitarios durante los siglos XX y XXI. El proceso ha sido complejo y cargado de tensiones.

Palabras clave: coronavirus; derechos sanitarios; salud pública; Argentina; historia.

\section{Abstract \\ The appearance of the first coronavirus cases in Argentina led to debate about features of the health care system and ways of accessing its services and benefits. This article reviews the moments when changes were made during the process of acquiring health care rights in the twentieth and twenty-first centuries. The process has been a complex and fraught one.}

Keywords: coronavirus; health care rights; public health; Argentina; history. 
$F_{d}$ rente al surgimiento de los primeros casos de coronavirus en la Argentina el 3 de marzo del 2020, las autoridades nacionales instaron, a partir del 20 de marzo, que todas las personas que habitan en el país o se encuentren en su territorio, en forma temporaria o definitiva, debían realizar el aislamiento social, preventivo y obligatorio para evitar el contagio de la covid-19. De esta manera, se impulsaron un conjunto de cambios en las prácticas individuales y colectivas vinculadas a la higiene, al distanciamiento físico y al uso de mascarillas como medidas para reducir el contagio. Estas recomendaciones fueron sugeridas con anticipación a la llegada de la mayor cantidad de casos de infectados que, en el caso de la Argentina, ocurrió a partir del mes de julio. Según las autoridades sanitarias la antelación de la implementación de las recomendaciones para evitar la enfermedad servía para ganar tiempo y, así, lograr aumentar la infraestructura sanitaria, ampliar la capacidad de camas instaladas en las unidades de terapia intensiva; preparar zonas de aislamiento en clubes, centros educativos y recreativos; incrementar y capacitar al personal sanitario en cuidados críticos; e intentar evitar el colapso del sistema de salud por la imposibilidad de satisfacer las demandas sanitarias que el coronavirus ocasiona cuando afecta a personas mayores o quienes tienen enfermedades preexistentes. Estas acciones contaron con el apoyo de la comunidad de científicos a nivel local e internacional y se adoptaron las recomendaciones indicadas por la Organización Mundial de la Salud y las experiencias formuladas en los países más afectados. El aislamiento, ante la ausencia de vacuna y tratamiento eficaz, es la única disposición que demostró cierta efectividad a la hora de menguar la propagación del virus.

El impacto de la covid-19 no discrimina en cuanto origen étnico, edad, género, tiene una mayor preponderancia de mortalidad entre adultos mayores y, como está siendo demostrado, quienes están al margen del acceso sanitario presentan mayores posibilidades de sufrir las consecuencias de la enfermedad. Es este último punto en el que me gustaría detenerme. La forma que se constituyó el sistema de salud en la Argentina y la concepción en torno al acceso de la salud como un derecho y su admisibilidad gratuita y universal está puesto en juego, una vez más, ante la emergencia de esta pandemia.

Desde la constitución del Estado moderno en la Argentina, a fines del siglo XIX, las instituciones sanitarias tuvieron un sostenimiento financiero público, privado y por origen étnico. Por un lado, hasta la primera mitad del siglo XX, la demostración de ser pobre, por medio de un certificado que probara tal situación, fue uno de los requisitos que se pedía al solicitar la admisión en los hospitales administrados por la sanidad pública (municipal, provincial, nacional) y por los gestionados por las sociedades filantrópicas o de beneficencia. Habitualmente eran lugares destinados a esperar la muerte ya que tenían muy pocas capacidades de cura debido a los altos niveles de contagio de las enfermedades imperantes y a la tecnología de la época que no permitía masificar los tratamientos. Por otro lado, se constituyeron hospitales de las colectividades cuyo acceso estuvo dado por la nacionalidad y por los aportes que los connacionales realizaban; así surgieron el Hospital Alemán, Británico, Francés, Español e Italiano. Por último, estaba el consultorio del médico, muchas veces instalado en su domicilio personal, lugar donde se podía dar algún tratamiento o brindar alguna farmacopea. El acceso a todas estas instancias convivió con vías alternativas de curar en manos de curanderos, barberos y las llamadas brujas (Belmartino, 2005). 
Este andamiaje institucional se fue gestando al calor de las urgencias que se producían frente a los reiterados brotes epidémicos, entre los cuales, el cólera y la fiebre amarrilla fueron los más dramáticos. Entonces, frente a las incertidumbres que se generaban ante una epidemia tanto las acciones del Estado como la de los lazaretos, de administración pública o privada, intentaban paliar las consecuencias de las llamadas miasmas sobre los cuerpos. Hacia los años 1920 los avances de la bacteriología moderna y los vínculos que se entablaron entre los médicos y el Estado dieron lugar a importantes avances en la investigación científica y en la salud pública que se evidenció en la reducción de la tasa de mortalidad infantil, las campañas de vacunación obligatoria y una densa red institucional en la ciudad de Buenos Aires y en las ciudades del litoral (Armus, 2007; Fiquepron, 2020).

A partir de los años 1940, y más particularmente durante la presidencia de Juan Domingo Perón (1946-1955), se generalizaron los avances tecnológicos y el hospital se convirtió en un centro de cura, prevención e investigación. Con estos cambios, en torno a cómo pensar el espacio hospitalario, se modificó su admisión. El ideal de la época y, a tono con lo que sucedía en otras latitudes en la segunda posguerra, el ser habitante del país daba derechos para obtener la ciudadanía sanitaria. Este concepto quedó plasmado en la reforma de la Constitución Nacional en 1949, ya que la salud sería un derecho social (art. 14), y en la reforma constitucional de 1994, cuando se reconoció expresamente el derecho a la salud (art. 75 inc. 22). Esta concepción se combinó durante los años del peronismo clásico (1945-1952) con la construcción de hospitales ligados al vínculo laboral; así surgieron, entre otros, el Hospital Ferroviario, el Policlínico de los Bancarios (Ramacciotti, 2009). Es decir, la rama de la actividad laboral fue una vía de acceso a las prestaciones de salud; este fue el antecedente al sistema de obras sociales el cual se consolidó en la década del 1970, momento en el cual los trabajadores y los empleadores debieron aportar de manera obligatoria para su sostenimiento.

Al despuntar la década de los 1960, también cobraron importancia los hospitales de gestión privada en los cuales la admisión se determinó por la lógica del mercado y del supuesto prestigio social a ellos atribuidos.

El sistema de salud de la Argentina se ha caracterizado como mixto, por combinar las iniciativas públicas con las privadas, y fragmentado, por su falta de coordinación y articulación que atenta contra el uso eficiente de recursos y niveles aceptables de equidad en su cobertura. Además, el sistema público ha sufrido en las últimas décadas momentos de desfinanciamiento y de fuertes críticas en torno a su acceso gratuito. Durante la década de 1990 se realizaron reformas en el sector salud que tuvieron como rasgo sobresaliente la imposición de un discurso que fomentaba la libre competencia entre los sistemas - y las empresas - y la libre elección de los ciudadanos, profundizando el individualismo. Por lo tanto, en términos discursivos se enunció la perentoria necesidad de profundizar la diferencia entre el sistema público de salud - destinado a los sectores más carenciados de la sociedad - con el sistema de las empresas de salud prepagas basadas en una lógica mercantil. Desde esta perspectiva, el Estado solo debería intervenir con el fin de aliviar los efectos de la pobreza y producir solo aquellos servicios que los privados no pudieran o no quisieran desarrollar. De esta forma, se permitió cobrar aranceles a las prestaciones que se brindaban a los pacientes que tuvieran algún tipo de cobertura y solo se mantuvo la gratuidad para las personas que carecieron de ella (Cerdá, Ramacciotti, 2015). 
El gobierno encabezado por la coalición Cambiemos (2015-2019) puso en marcha un agresivo plan de redistribución regresiva del ingreso, apoyado por una alianza con los sectores financieros, agrarios, energéticos, telecomunicaciones, y los medios (Canelo, 2019). El sector privado tuvo en sus manos el diseño y la puesta en práctica de políticas públicas que en el ámbito de la ciencia y la salud pública condujo a una campaña de desprestigio de lo público con el objetivo de desmantelar las responsabilidades estatales en materia de salud, investigación y educación y avanzar en su desfinanciamiento. Entre algunas de las acciones tomadas por el presidente Mauricio Macri fue la de transformar el Ministerio de Salud Pública en la Secretaría. Con esta medida, esta dependencia estatal pasó a estar bajo la tutela del Ministerio de Desarrollo Social lo que llevó implícito una reducción de la autonomía en la gestión y de partidas presupuestarias, en áreas en las cuales los recursos siempre son escasos para satisfacer demandas cada vez más complejas. También, se redujo la entrega de anticonceptivos en los centros de salud, se dificultó el acceso a las vacunas contra el sarampión y la gripe A entre la población en riesgo; se desmanteló gran parte de las prestaciones de salud destinadas a la tercera edad que brinda el Instituto Nacional de Servicios Sociales para Jubilados y Pensionados, más conocido como Pami, desde 1971.

En esta situación, en diciembre del 2019, asumió el gobierno Alberto Fernández, quien se identifica con el movimiento peronista, y a solo tres meses de asumir el cargo, en medio de una profunda crisis económica y social, se tuvieron que activar los mecanismos institucionales y presupuestarios para enfrentar la segunda pandemia del siglo XXI. Dentro de la agenda de gobierno, la salud se puso como tópico central; según las palabras del presidente "de la economía se vuelve, de la muerte no se vuelve más". La contundencia de esta afirmación intentó contrarrestar las presiones de poderosos actores económicos, políticos y de ciertos medios de comunicación quienes sostenían la importancia de priorizar la economía antes que la salud. El gobierno nacional ha tomado las riendas del diseño e implementación de la política sanitaria y mantiene una fuerte vocación por reconstruir los valores y el influjo que alguna vez supo tener el hospital público y la investigación científica. Dicha gesta no es fácil, los insumos críticos escasean, los profesionales de salud se están contagiando, en algunas provincias no se cuenta con los recursos humanos capacitados para atender a los pacientes que se encuentran en situación crítica, los recursos del Estado no alcanzan, las medidas para aumentar la recaudación fiscal no cuentan con los acuerdos políticos necesarios y las dificultades para sostener por tantos meses el aislamiento reducen las posibilidades de evitar los contagios. Además, el sostenimiento del aislamiento social, preventivo y obligatorio, afecta con dureza a quienes están en los márgenes de la sociedad, en situación de pobreza o de inestabilidad económica, a quienes sufren las consecuencias del encierro, ya sea por la reducción de tratamientos psicológicos y por el incremento de la violencia doméstica, y las aguas están divididas en torno a los efectos de esta situación para la salud psíquica de la infancia y la adolescencia.

Dentro de los escenarios posibles que tendremos que sortear en la salida de la pandemia, espero que nos encuentre con lazos de solidaridad más sólidos y que en las decisiones políticas prime la importancia de fomentar un debate para lograr el mejoramiento de las condiciones laborales del personal de salud y poder sostener un sistema de salud público que ofrezca sus servicios de manera universal y gratuita. Esto implica que todo ciudadano 
tenga derecho a recibir una cobertura básica y, de esta forma, reforzar el rasgo distintivo del sistema de salud argentino. La salud pública no es una cuestión individual o que puede ser regulada por la lógica del libre funcionamiento del mercado. La atención de la salud es diferente de casi todos los demás bienes y servicios y por ello debe basarse en la existencia de un derecho para todas las personas. Solo el Estado está en condiciones de garantizar la igualdad de oportunidades en el acceso a la salud por parte de la mayoría de la población y de ocuparse responsablemente de la fiscalización y de la regulación de las acciones de interés público dirigidas a asegurar la protección de la salud colectiva y de esta forma intentar reducir las desigualdades sociales.

\section{NOTA}

* El siguiente texto es una versión más completa, actualizada y sometida a revisión de pares de un post que apareció en el blog de História, Ciências, Saúde - Manguinhos.

\section{REFERENCIAS}

ARMUS, Diego. La ciudad impura: salud, tuberculosis y cultura en Buenos Aires, 1870-1950. Buenos Aires: Edhasa, 2007.

BELMARTINO, Susana. La atención médica argentina en el siglo XX. Instituciones $y$ procesos. Buenos Aires: Siglo XXI, 2005.

CANELO, Paula. ¿Cambiemos? La batalla cultural por el sentido común de los argentinos. Buenos Aires: Siglo XXI, 2019.

CERDÁ, Juan Manuel; RAMACCIOTTI, Karina. Las políticas de salud en la década de 1990.
In: Biernat, Carolina; Cerdá, Juan Manuel; Ramacciotti, Karina (dir.). La salud pública y la enfermería en la Argentina. Bernal: Universidad Nacional de Quilmes, 2015. p.229-254.

FIQUEPRON, Maximiano. Morir en las grandes pestes: las epidemias de cólera y fiebre amarilla en la Buenos Aires del siglo XIX. Buenos Aires: Siglo XXI, 2020.

RAMACCIOTTI, Karina. La política sanitaria del peronismo. Buenos Aires: Biblos, 2009. 